\title{
A New CPW-Fed Diversity Antenna for MIMO 5G Smartphones
}

\author{
Naser Ojaroudi Parchin ${ }^{1, *(1)}$, Haleh Jahanbakhsh Basherlou ${ }^{2}{ }^{(0}$, Yasir I. A. Al-Yasir ${ }^{1}{ }^{(1)}$, \\ Ahmed M. Abdulkhaleq ${ }^{1,3}$, Mohammad Patwary ${ }^{4}$ and Raed A. Abd-Alhameed ${ }^{1}(\mathbb{D}$ \\ 1 Engineering and Informatics, University of Bradford, Bradford BD7 1DP, UK; \\ Y.I.A.Al-Yasir@bradford.ac.uk (Y.I.A.A.-Y.); A.Abd@sarastech.co.uk (A.M.A.); \\ R.A.A.Abd@bradford.ac.uk (R.A.A.-A.) \\ 2 Bradford College, Bradford BD7 1AY, UK; Hale.Jahanbakhsh@gmail.com \\ 3 SARAS Technology Limited, Leeds LS12 4NQ, UK \\ 4 School of Computing and Digital Technology, Birmingham City University, Birmingham B5 5JU, UK; \\ Mohammad.patwary@bcu.ac.uk \\ * Correspondence: N.OjaroudiParchin@Bradford.ac.uk; Tel.: +447341436156
}

Received: 31 December 2019; Accepted: 28 January 2020; Published: 4 February 2020

\begin{abstract}
In this study, a new coplanar waveguide (CPW)-fed diversity antenna design is introduced for multiple-input-multiple-output (MIMO) smartphone applications. The diversity antenna is composed of a double-fed CPW-fed antenna with a pair of modified T-ring radiators. The antenna is designed to cover the frequency spectrum of commercial sub-6 GHz 5G communication (3.4-3.8 and 3.8-4.2 GHz). It also provides high isolation, better than $-16 \mathrm{~dB}$, without an additional decoupling structure. It offers good potential to be deployed in future smartphones. Therefore, the characteristics and performance of an 8-port 5G smartphone antenna were investigated using four pairs of the proposed diversity antennas. Due to the compact size and also the placement of the elements, the presented CPW-fed smartphone antenna array design occupies a very small part of the smartphone board. Its operation band spans from 3.4 to $4.4 \mathrm{GHz}$. The simulated results agree well with measured results, and the performance of the smartphone antenna design in the presence of a user is given in this paper as well. The proposed MIMO design provides not only sufficient radiation coverage supporting different sides of the mainboard but also polarization diversity.
\end{abstract}

Keywords: 5G technology; CPW-fed antenna; diversity antenna; future smartphones; MIMO systems

\section{Introduction}

With the creation of standards for and the development of fifth-generation (5G) mobile communication, more and more research has been conducted into related technologies with the hope of achieving a higher transmission rate, lower cost and higher gain [1-3]. Multiple-input-multiple-output (MIMO) technology is a key to realizing a higher transmission rate [4]. By using MIMO technology, multiple independent channels can be achieved on the original spectrum by the diversity method, and multipath fading can be reduced so as to improve the data transmission rate. A MIMO antenna is a significant facility to improve the channel capacity of a MIMO system [5-8]. MIMO systems of 2 $\times 2$ are successfully employed for $4 \mathrm{G}$ mobile networks, and a large number of antenna elements are expected to be applied for $5 \mathrm{G}$ communications $[9,10]$.

Several kinds of 5G MIMO smartphone antennas have been put forward recently [11-25] (see Table 2 for details). However, these MIMO antenna designs either suffer from a narrow frequency bandwidth or occupy a huge space on a smartphone mainboard. Furthermore, some of the reported designs use uniplanar radiators, which are difficult to fabricate and integrate with the 5G smartphone 
circuit. In the designs of many MIMO antennas, it is common to avoid placing elements in parallel and to choose instead to place them vertically, which can avoid strong mutual couplings caused by the same polarization mode. In this paper, however, the antenna elements are both perpendicular and parallel to each other to exhibit the diversity function. In addition, the T-shaped strip of the antenna configuration can act as a decoupling structure. Due to compact size and also placement of the antenna, the proposed MIMO design occupies a very small part of the smartphone printed circuit board (PCB). Therefore, the antenna achieves not only low mutual couplings but also small clearance.

The antenna elements of the MIMO design are fed using the coplanar waveguide feeding mechanism in order to operate at sub-6 GHz 5G communication (3.4-3.8 and 3.8-4.2 GHz) [26]. Compared with probe-fed and microstrip-fed antennas, coplanar waveguide (CPW)-fed antennas can easily achieve the wideband impedance matching [27,28]. Therefore, CPW-fed antennas are widely used and becoming increasingly popular in wireless applications owing to their attractive features such as compact size, conformal status, their light weight and ease of fabrication and integration with wireless communication systems $[29,30]$. The paper is organized as follows: The design and characteristics of the diversity antenna element are represented in Section 2. Section 3 discusses the MIMO performance and radiation characteristics of the proposed 5G smartphone antenna array. Section 4 investigates the radiation behavior of the designed smartphone antenna array in the vicinity of the user. Section 5 gives the conclusion of this paper.

\section{The Proposed CPW-Fed Diversity Antenna}

The characteristics of the single-element diversity antenna are discussed in this section. Its structure is shown in Figure 1a. It is shown that the schematic of the diversity antenna contains a pair of modified CPW-fed T-ring resonators. As seen, the proposed antenna is designed on one side of the FR4 dielectric. In addition, as seen, SMA (SubMiniature version A) connectors are also embedded in the simulations. Figure $1 \mathrm{~b}$ depicts the S-parameters of the proposed $\mathrm{CPW}$-fed diversity antenna. As illustrated, the designed antenna provides a wide operation band of 3.2-4.4 GHz, supporting both target bands, including 3.4-3.8 and 3.8-4.2 GHz. It should be noted that the arrow-shaped strip of the design, placed between the elements, can act as a decoupling structure and increase the isolation between the antenna ports. Therefore, the mutual coupling $\left(\mathrm{S}_{12} / \mathrm{S}_{21}\right)$ is successfully reduced. As can be observed, greater than $-15 \mathrm{~dB}$ (with $-20 \mathrm{~dB}$ value at the center frequency $(4 \mathrm{GHz})$ ) has been achieved for the designed diversity antenna. The characteristics of the antenna are investigated using computer simulation technology (CST) software [31]. The detailed dimensions of the designed CPW-fed diversity antenna are shown in Table 1.

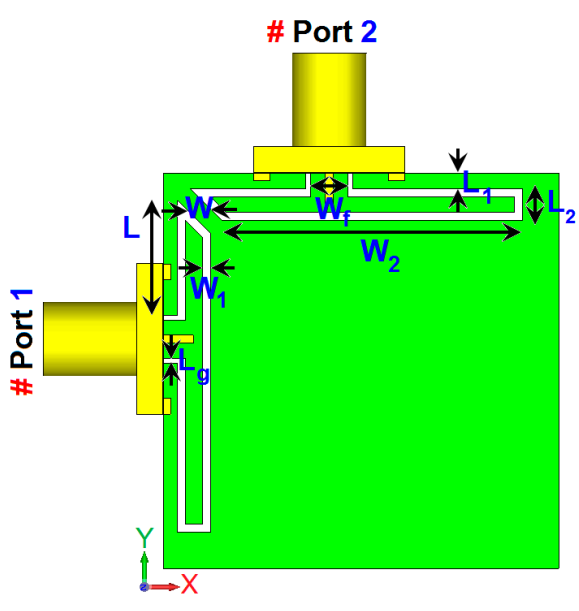

(a)

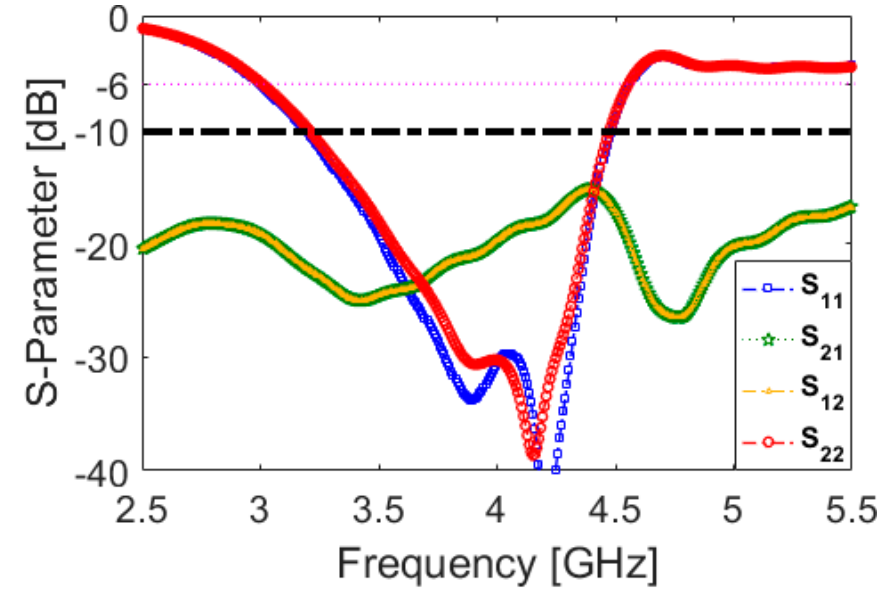

(b)

Figure 1. (a) Geometry of the coplanar waveguide (CPW)-fed diversity antenna and (b) its simulated S-parameters. 
Table 1. The dimension of the diversity antenna.

\begin{tabular}{cccccccc}
\hline Parameter & Value $(\mathbf{m m})$ & Parameter & Value $(\mathbf{m m})$ & Parameter & Value $(\mathbf{m m})$ & Parameter & Value $(\mathbf{m m})$ \\
\hline $\mathrm{W}$ & 1.1 & $\mathrm{~W}_{1}$ & 0.5 & $\mathrm{~W}_{2}$ & 19 & $\mathrm{~W}_{\mathrm{f}}$ & 2.4 \\
$\mathrm{~L}$ & 7 & $\mathrm{~L}_{1}$ & 1 & $\mathrm{~L}_{2}$ & 2 & $\mathrm{~L}_{\mathrm{g}}$ & 0.25 \\
\hline
\end{tabular}

The frequency behavior of the proposed diversity antenna is very flexible. Figure 2 discusses the impedance matching and frequency tuning of the antenna. Figure 2a illustrates the $S_{11}$ and $S_{21}$ characteristics versus different values of $\mathrm{W}_{2}$. As seen, when its value increases from 17 to $21 \mathrm{~mm}$, the lower and upper operation frequencies of the antenna increase from 3 to 3.4 and 4.5 to $4.8 \mathrm{GHz}$, respectively. In addition, as can be observed, the $S_{21}$ function of the diversity antenna tunes by changing the value of $\mathrm{W}_{2}$. Figure $2 \mathrm{~b}$ investigates the impedance matching function of the antenna for various values of $\mathrm{L}_{2}$ : when its size changes from 2.75 to $1.75 \mathrm{~mm}$, the matching characteristic of the diversity antenna varies from -14 to less than $-30 \mathrm{~dB}$. However, unlike Figure $2 \mathrm{a}$, the $S_{21}$ is almost constant with an insignificant variation.
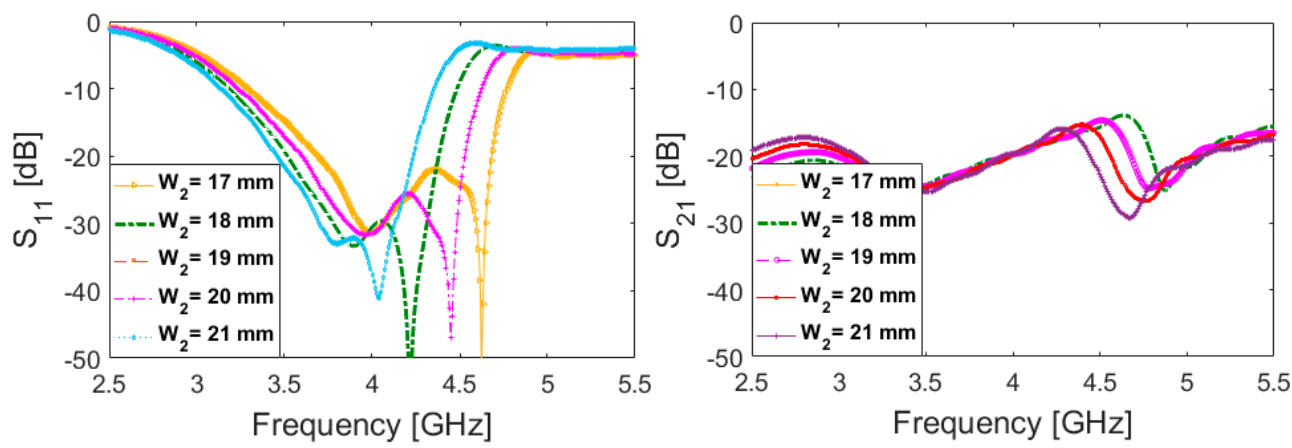

(a)
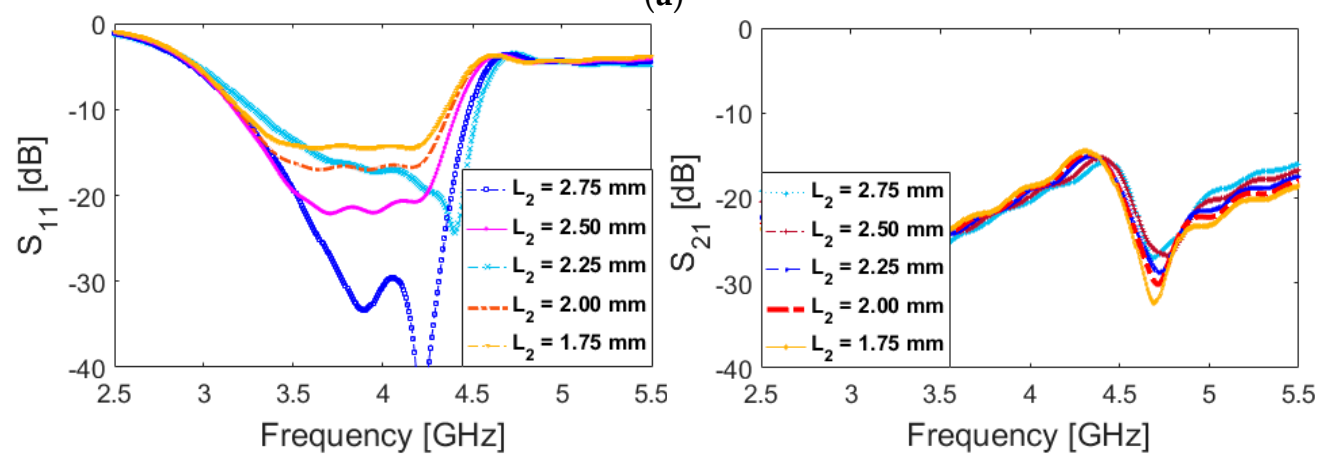

(b)

Figure 2. $S_{11} / S_{21}$ results of the diversity antenna for various values of (a) $W_{2}$ and (b) $L_{2}$.

In order to have a better illumination about the working mechanism of the CPW-Fed, its simulated current distributions at 3.8 and $4.2 \mathrm{GHz}$ are shown in Figure 3. As shown at $3.8 \mathrm{GHz}$, the current is mainly distributed near the arrow strip and outer boundary of the modified T-ring resonator, which verifies the role of the strip in creating a new resonance at $3.8 \mathrm{GHz}$. At $4.2 \mathrm{GHz}$, the currents are mainly concentrated inside of the modified T-ring slot [31,32]. The radiation patterns of the diversity antenna for each exciting port at $4 \mathrm{GHz}$ (center frequency of the antenna operation band) are plotted in Figure 4. It is shown that well-defined polarization and pattern diversity is obtained for the antenna. The radiation patterns of the antenna are symmetrical, covering the top/bottom sides of the substrate and providing similar radiation behavior with a gain value of $3.6 \mathrm{~dB}$. The fundamental radiation characteristics of the diversity antenna are also given in Figure 5 within the range of $3.4-4.4 \mathrm{GHz}$ (with $0.1 \mathrm{GHz} /$ step). As illustrated in Figure 5, the antenna exhibits high efficiencies over its $1 \mathrm{GHz}$ 
impedance bandwidth. In addition, the antenna offers sufficient gain and directivity in the range of 3.4-4.4 GHz.

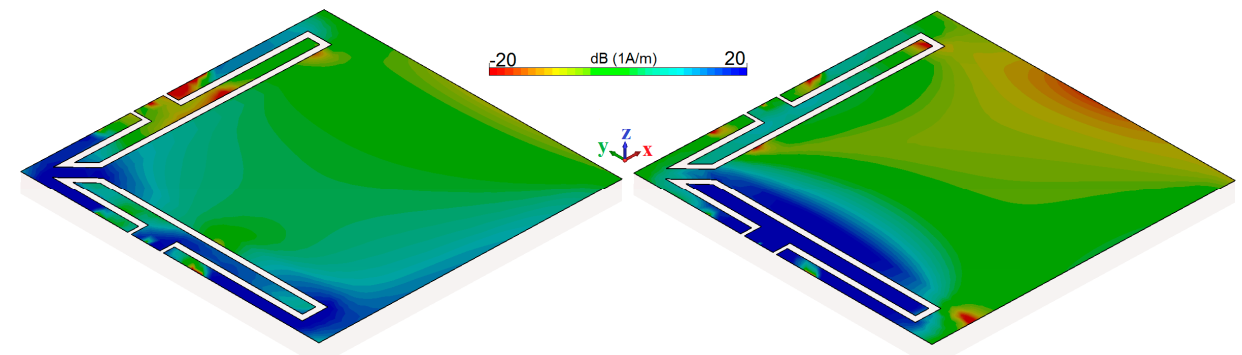

(a)

(b)

Figure 3. The current densities of the diversity antenna design from port 1 at (a) 3.8 and (b) $4.2 \mathrm{GHz}$.

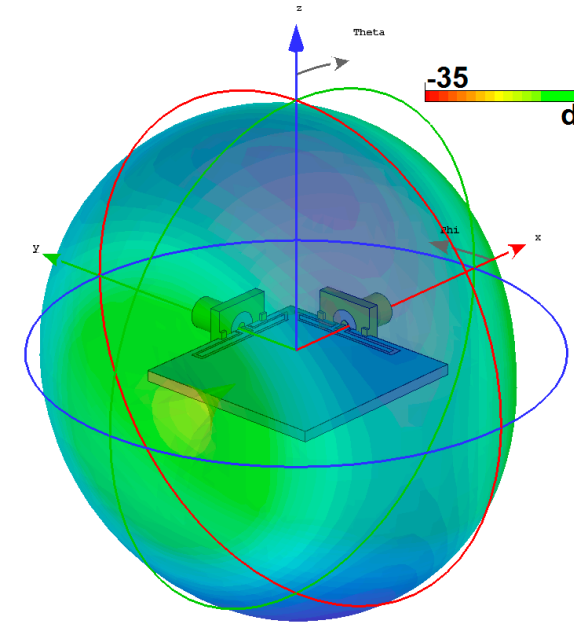

(a)

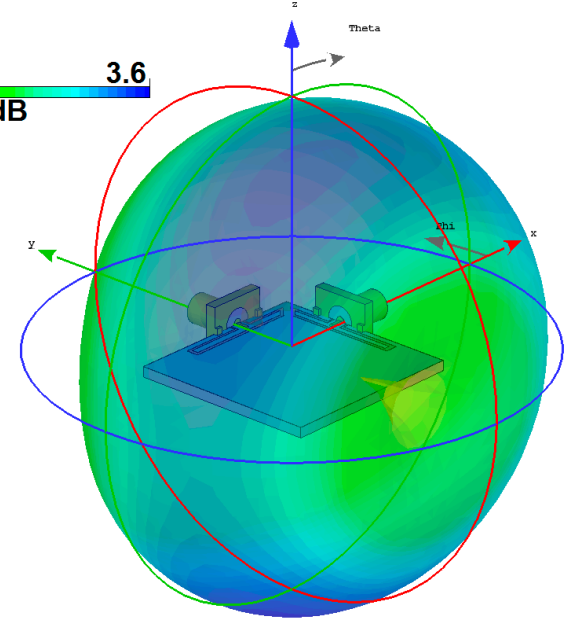

(b)

Figure 4. Radiation patterns of the CPW-fed diversity antenna at $4 \mathrm{GHz}$ from (a) ports 1 and (b) 2.

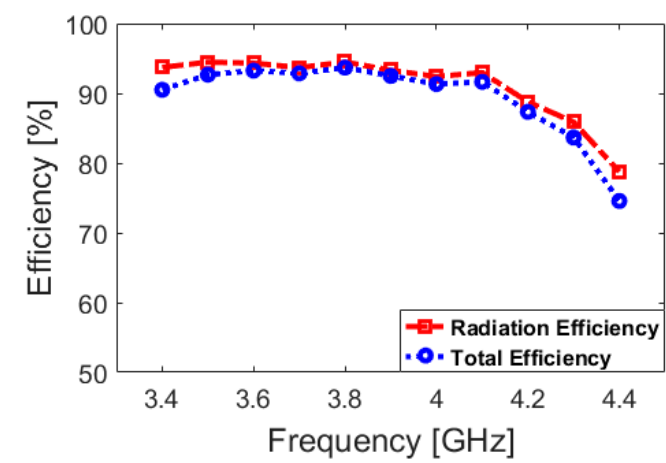

(a)

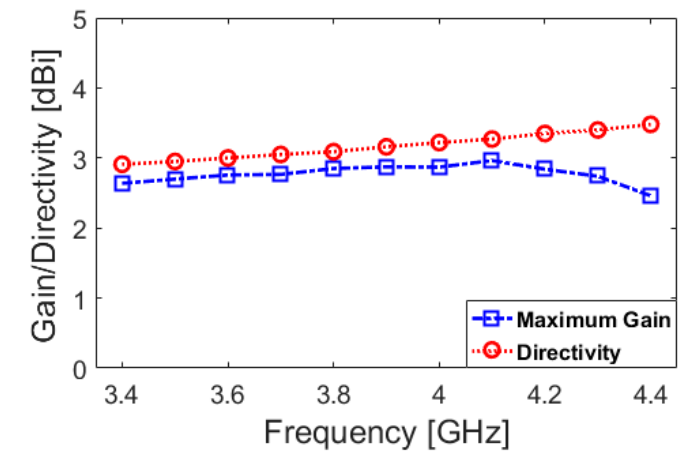

(b)

Figure 5. Simulated (a) efficiency and (b) gain/directivity characteristics of the CPW-fed antenna.

A prototype of the design was fabricated and its $S$ parameters were tested. In order to verify the simulated S-parameter results mentioned above, the single-element diversity antenna was fabricated and measured. A vector network analyzer was used to measure the antenna in our research. The fabricated dual-port antenna and the measured results of S-parameters are given in Figure 6a,b. As illustrated in Figure 6b, the measured results of the diversity antenna based on FR-4 are very close to the simulated results' values within $2.5-5.5 \mathrm{GHz}$; it provides quite a good impedance bandwidth $\left(\mathrm{S}_{11}<\right.$ $-10 \mathrm{~dB}$ within $3.2-4.4 \mathrm{GHz})$, and its mutual coupling $\left(\mathrm{S}_{21}\right)$ is less than $-15 \mathrm{~dB}$. 


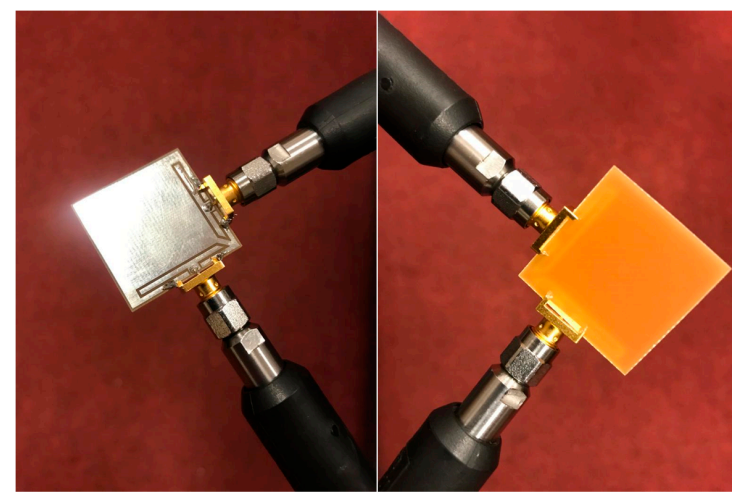

(a)

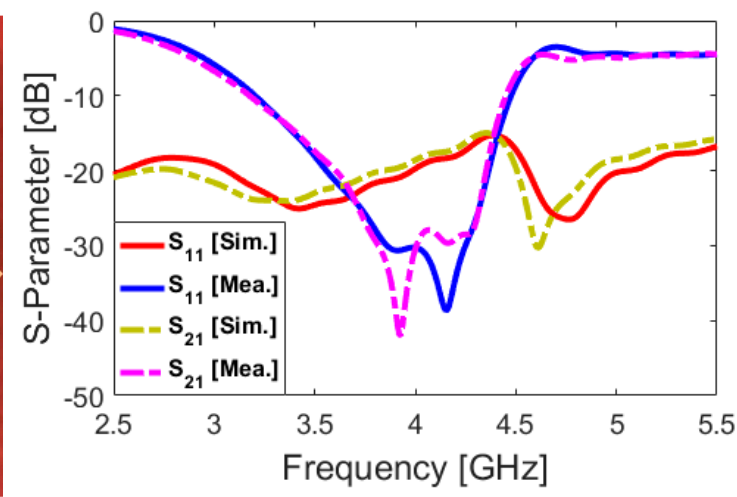

(b)

Figure 6. (a) Fabricated antenna's top/bottom sides and (b) the simulated/measured S-parameters.

The total active reflection coefficient (TARC), envelope correlation coefficient (ECC) and diversity gain (DG) characteristics are important parameters to be considered in diversity/MIMO antennas and can be calculated using the below formulas [33-35].

$$
\begin{gathered}
\text { TARC }=-\sqrt{\frac{\left(S_{11}+S_{12}\right)^{2}+\left(S_{21}+S_{22}\right)^{2}}{2}} \\
E C C=\frac{\left|S_{11}^{*} S_{21}+S_{12}^{*} S_{22}\right|^{2}}{\left(1-\left|S_{11}\right|^{2}-\left|S_{12}\right|^{2}\right)\left(1-\left|S_{21}\right|^{2}-\left|S_{22}\right|^{2}\right)^{*}} \\
D G=10 \sqrt{1-(E C C)^{2}}
\end{gathered}
$$

Figure 7 represents the calculated TARC, ECC and DG characteristics for the proposed dual-port diversity antenna. As shown in Figure 7a,b, the TARC and ECC results of this diversity antenna are very low within the band, which means the antenna is competent for diversity reception/transmission in the MIMO channels [33]. In addition, as can be observed from Figure 7c, the DG function of the design is greater than $9.97 \mathrm{~dB}$ over the entire band.

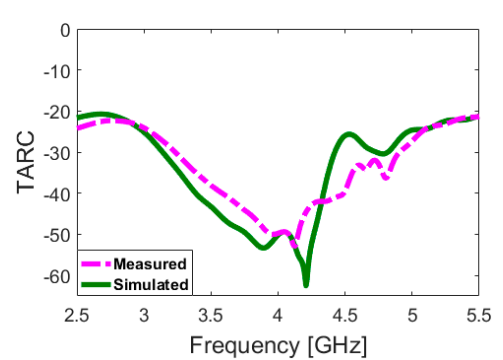

(a)

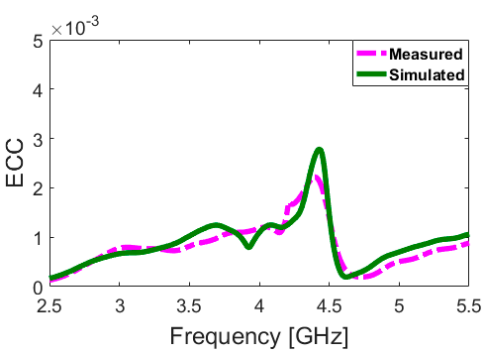

(b)

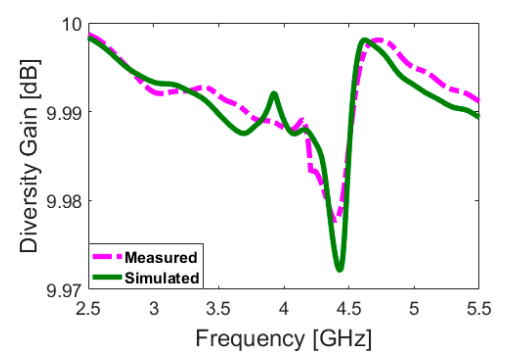

(c)

Figure 7. Calculated (a) total active reflection coefficient (TARC), (b) envelope correlation coefficient (ECC) and (c) diversity gain (DG) characteristics of the CPW-fed diversity antenna.

\section{Mobile-Phone Antenna Design}

Four pairs of the modified CPW-fed diversity antenna mentioned above were placed in different corners of the smartphone board to form an eight-port MIMO antenna with a standard size of $150 \times 75$ $\times 1.6 \mathrm{~mm}^{3}$. Its structure is shown in Figure 8. As can be observed, due to the compact size and also the placement of the $\mathrm{CPW}$-fed ring antenna, the proposed MIMO design occupies a very small part of the board. 
Figure 9 shows the S-parameters of the CPW-fed MIMO smartphone antenna. It can be observed from Figure 9a that all antenna elements exhibit good return loss results covering 3.4-4.4 GHz. It should also be noted that due to the effect of the MIMO configuration and also the big ground plane of the smartphone board, the lower operation frequency shifted from 3.2 to $3.4 \mathrm{GHz}$. However, it still covers the target 5G bands including 3.4-3.8 and 3.8-4.2 GHz. The isolations between ports are shown in Figure $9 \mathrm{~b}$. The maximum mutual couplings of the diversity antenna arrays are usually between the closely spaced diversity elements such as Ant. 1 and Ant. 2. Due, however, to similar performances and placements of the antenna pairs in the configuration of the proposed smartphone antenna, it is not necessary to show all S-parameters. As seen from Figure 9b, the isolation levels of the antenna ports are less than $16 \mathrm{~dB}$ within 3.4-4.4 GHz. This is mainly due to the strong mutual couplings between the adjacent ports. Figure 10 plots the radiation patterns at the middle frequency $(4 \mathrm{GHz})$ of the first $\mathrm{CPW}$-fed diversity antenna (with ports 1 and 2) mounted onto the smartphone PCB. As seen, the radiation patterns are symmetrical covering the top/bottom sides of the substrate and providing similar radiation behavior with gain vale of $4 \mathrm{dBi}$.

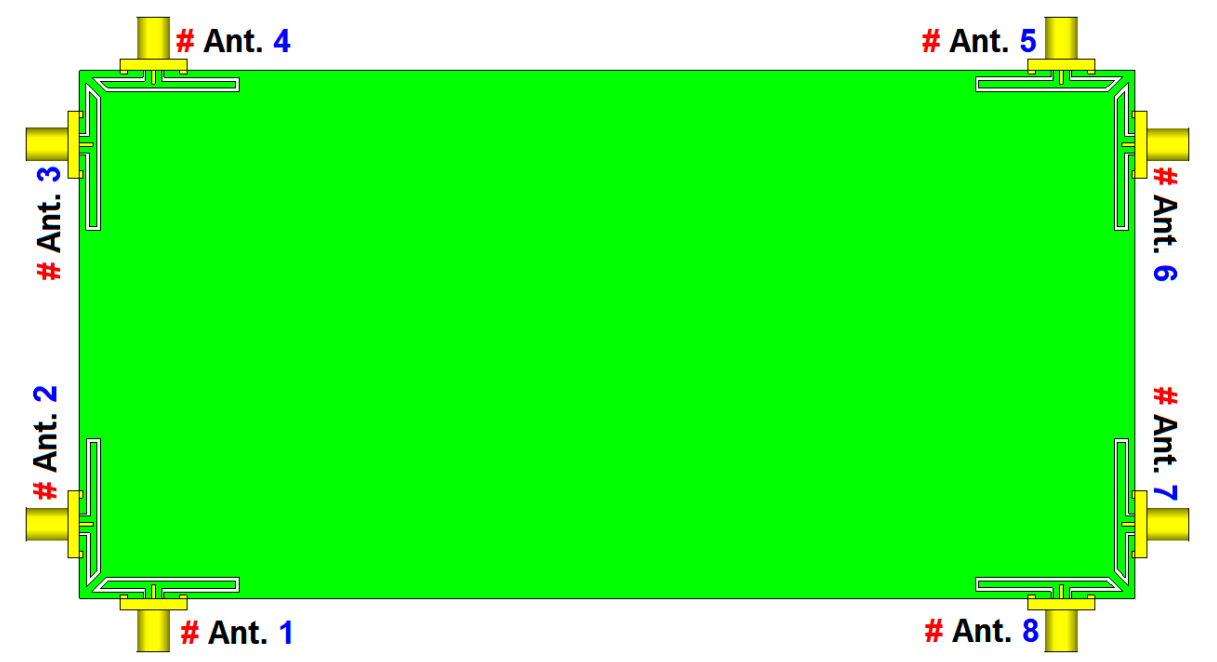

Figure 8. Schematic of the CPW-fed eight-port 5G smartphone antenna.

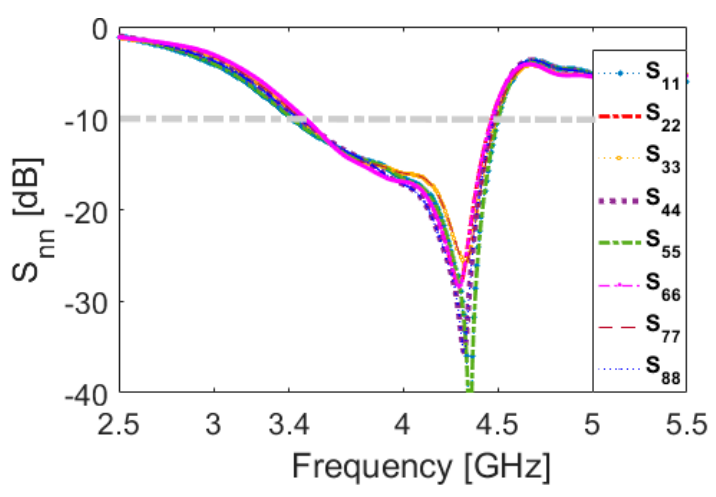

(a)

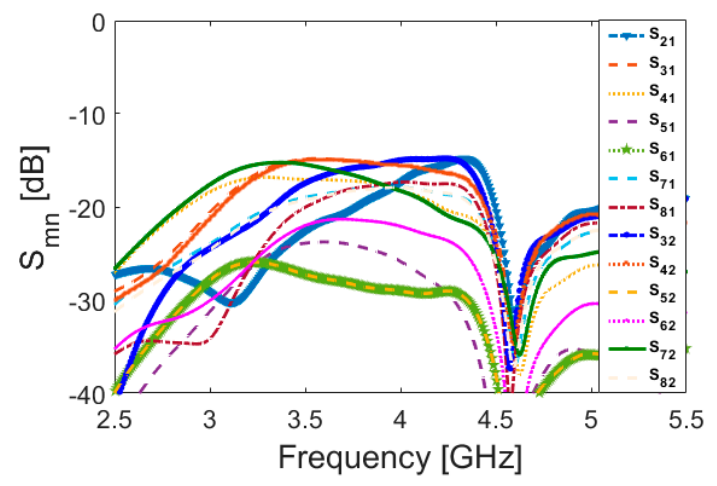

(b)

Figure 9. The simulated (a) $S_{\mathrm{nn}}$ and (b) $S_{\mathrm{mn}}$ results.

The 3D patterns of antenna radiations at $4 \mathrm{GHz}$ for each feeding port have been illustrated in Figure 11. It can be observed that the CPW-fed resonators not only can cover different sides of the mobile-phone board but also support different polarizations, which is a unique function of the MIMO design [36,37]. In addition, due to the different placements of antenna elements (Ant. 1 and Ant. 2, for example), gain values of 4.6/5.15 dB are achieved for the resonators. The efficiencies (radiation and total) of the CPW-fed ring slot resonators are also given in Figure 12. It is evident that high efficiencies 
with slight variations are achieved within the range of $3.4-4.4 \mathrm{GHz}$ : more than $80 \%$ radiation and $70 \%$ total efficiencies were observed for the CPW-fed elements of the proposed MIMO design.

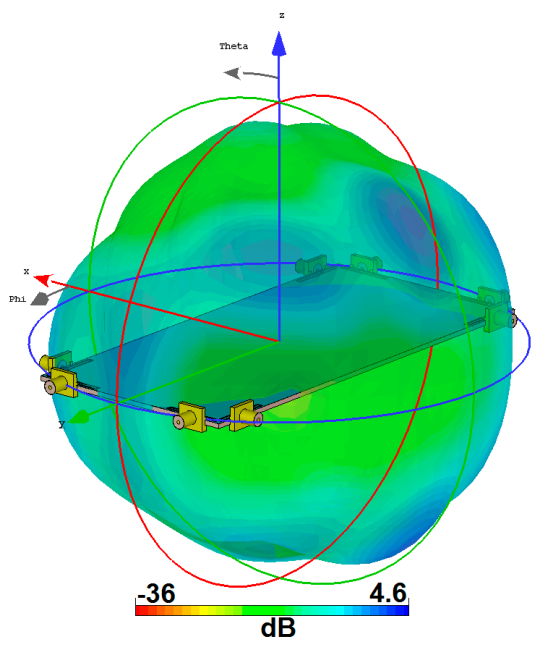

(a)

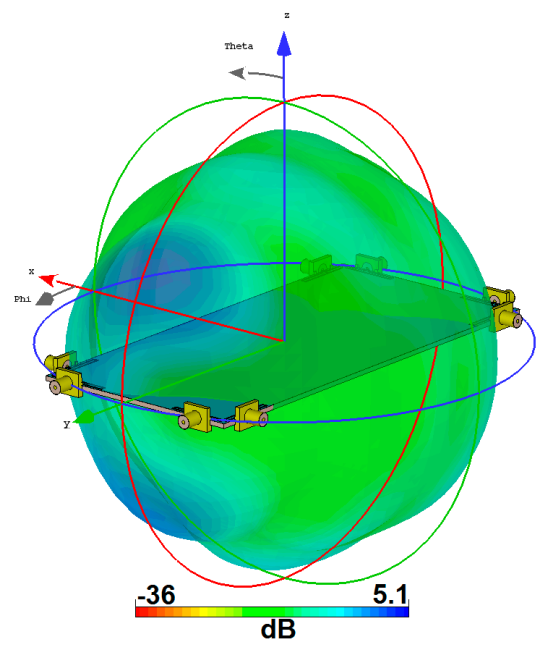

(b)

Figure 10. Radiation patterns of the dual-port diversity resonator from (a) port 1 and (b) port 2.

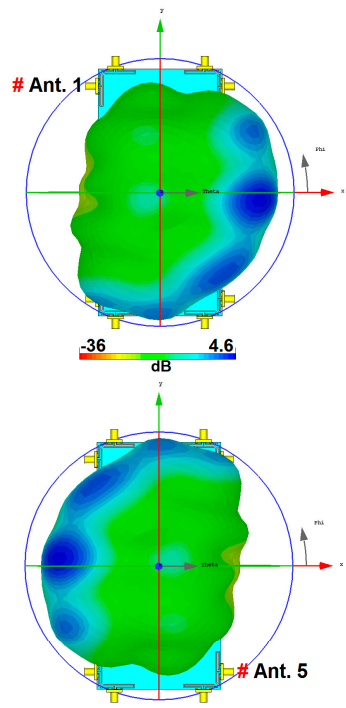

\begin{tabular}{lll}
-36 & 4.6 \\
\hline
\end{tabular}
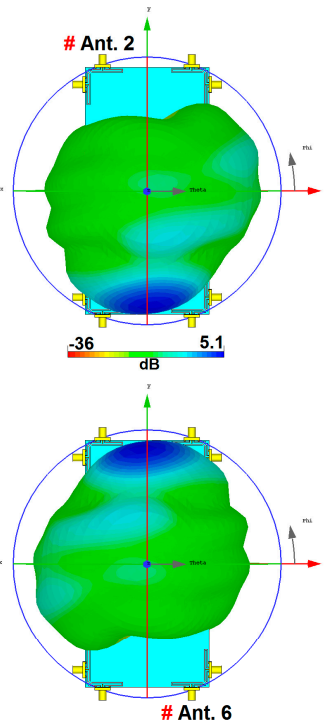

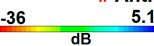

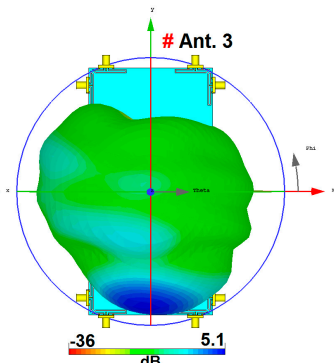

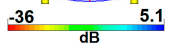

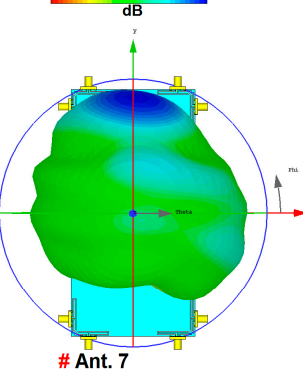

\begin{tabular}{ll}
-36 & 5.1 \\
\hline
\end{tabular}

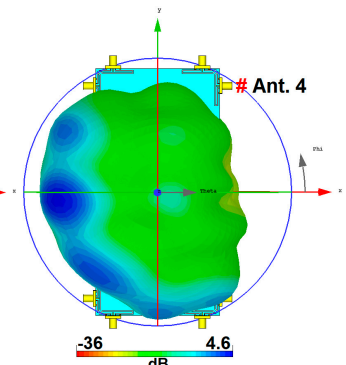

\begin{tabular}{lll}
-36 & 4.6 \\
\hline
\end{tabular}
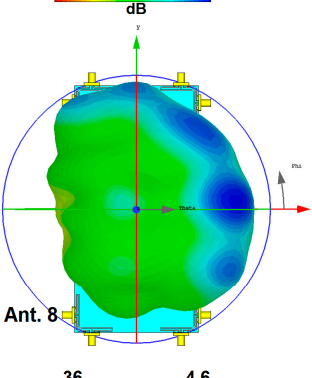

\begin{tabular}{llr}
-36 & 4.6 \\
\hline
\end{tabular}

Figure 11. 3D radiation patterns at center frequency $(4 \mathrm{GHz})$.

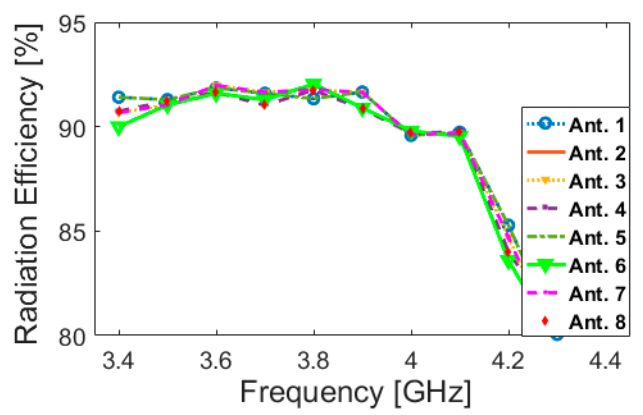

(a)

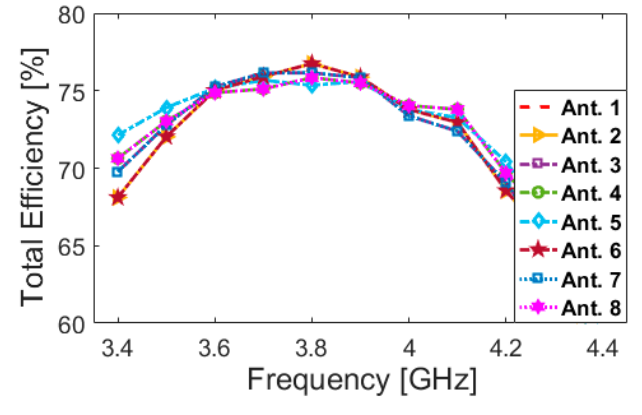

(b)

Figure 12. (a) Radiation and (b) total efficiencies of the antenna elements (Ant. 1-Ant. 8). 
A prototype of the $5 \mathrm{G}$ smartphone antenna design was fabricated and fed for measurements, as illustrated in Figure 13. In order to verify the simulated results of the smartphone antenna-mentioned above- the S-parameter and radiation patterns were measured. Due, however, to similar placements and also the performances of the CPW-fed antenna pairs, the properties of the smartphone antenna design for port 1 and 2 were measured and compared in the following way. A vector network analyzer and antenna chamber room were used in the measurement process in our research. The feeding mechanism of the design is shown in Figure 14a. During the measurements, in order to avoid unwanted mutual effects, $50-\Omega$ RF loads are installed for the elements not under test. The measured and simulated results of the S-parameters are compared in Figure 14b. As seen, the measured results are in good agreement with the simulated results to cover the required operation band: a quite good impedance bandwidth $\left(\mathrm{S}_{11}<-10 \mathrm{~dB}\right.$ within $\left.3.4-4.4 \mathrm{GHz}\right)$ and mutual coupling $\left(\mathrm{S}_{21}<-15 \mathrm{~dB}\right)$ are obtained for the smartphone antenna design.

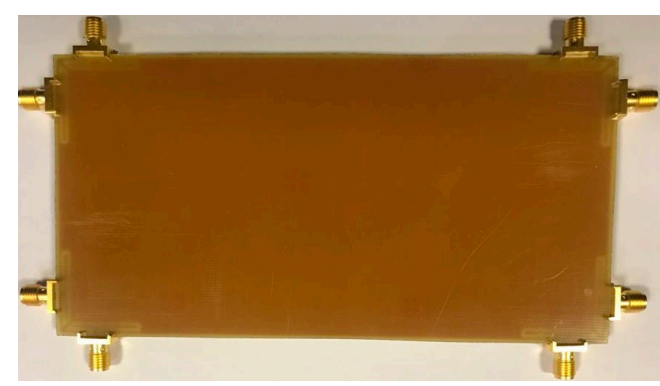

(a)

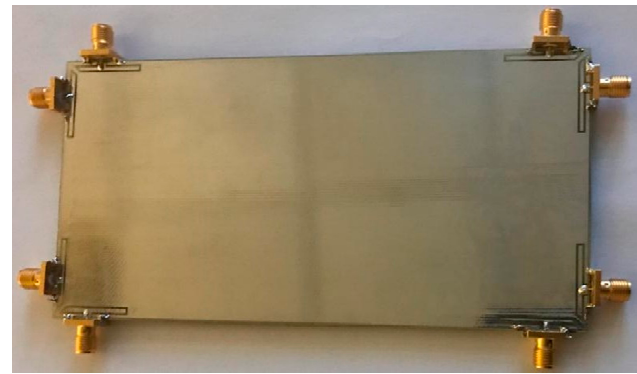

(b)

Figure 13. (a) Front and (b) back views of the fabricated sample.

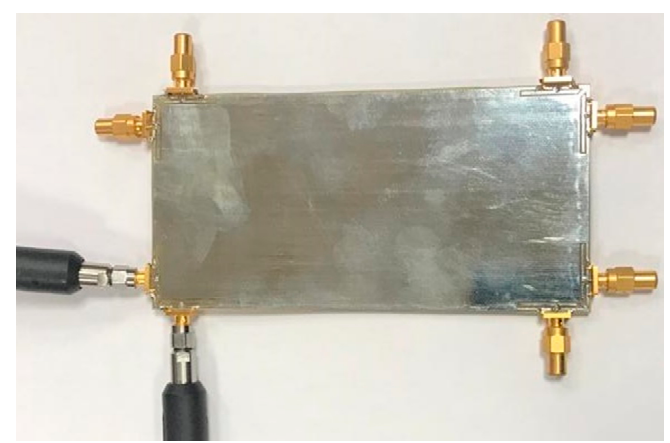

(a)

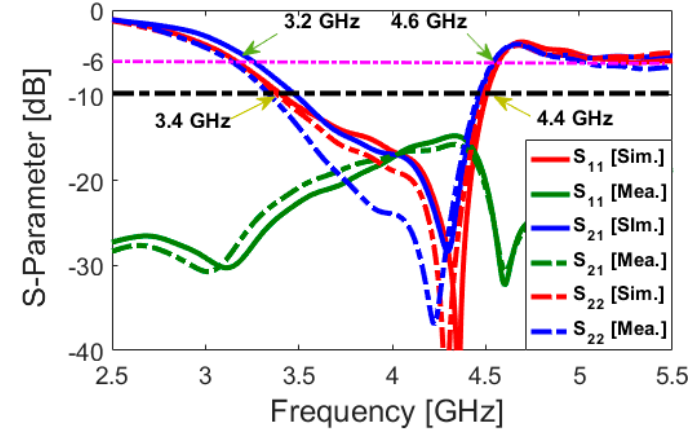

(b)

Figure 14. (a) Feeding mechanism and (b) S-parameters of adjacent CPW-fed elements for the 5G smartphone antenna.

Measured and simulated radiation patterns are shown in Figure 15. When measuring radiation patterns, we keep one port excited and another one loaded with a $50-\Omega$ load. In the measurement of radiation patterns, the smartphone MIMO antenna is used as the receiver, and a horn antenna is used as the transmitter. As can be observed from Figure $15 \mathrm{a}, \mathrm{b}$, the sample smartphone antenna prototype offers good quasi-omnidirectional radiation patterns with an acceptable agreement between simulations and measurements [38-40].

Table 2 provides a comparison between the presented smartphone array antenna and another reported smartphone array [11-25]. As can be observed, compared with the recently proposed 5G MIMO smartphone antennas with planar and uniplanar structures, our antenna performs better in terms of impedance match and bandwidth, and its clearance size remains at a satisfactory level, as shown in Table 2 . The proposed design achieves not only approximately $1 \mathrm{GHz}$ impedance bandwidth but also sufficient mutual couplings, better than $-15 \mathrm{~dB}$. Unlike the reported $5 \mathrm{G}$ antenna design, our 
antenna is implemented in one-side of the smartphone mainboard using CPW-fed technology, which makes it easy to fabricate and integrate with the circuit. It is apparent that all the listed antennas have double-sides or uniplanar configuration. In addition, due to the small clearance of the proposed smartphone antenna, its fundamental radiation properties in data and talk modes are not reduced significantly, as discussed in the following section.

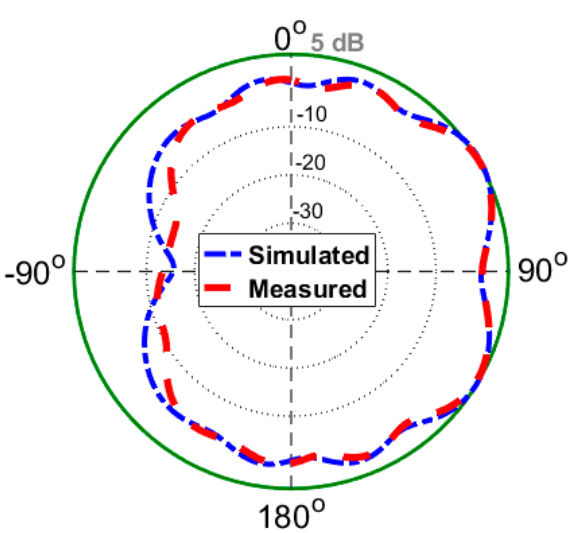

(a)

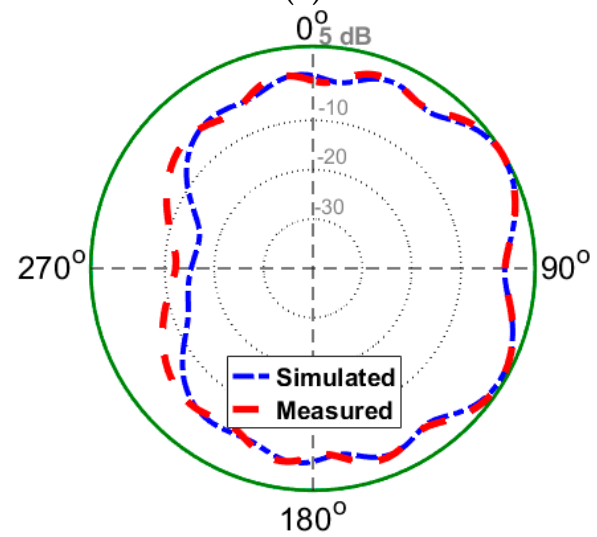

(c)

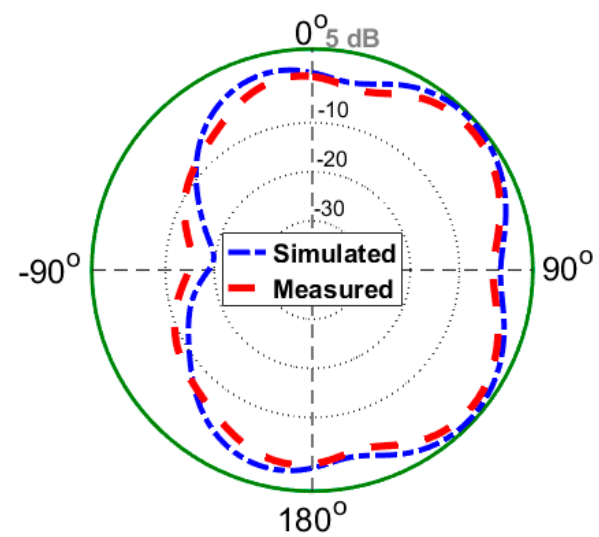

(b)

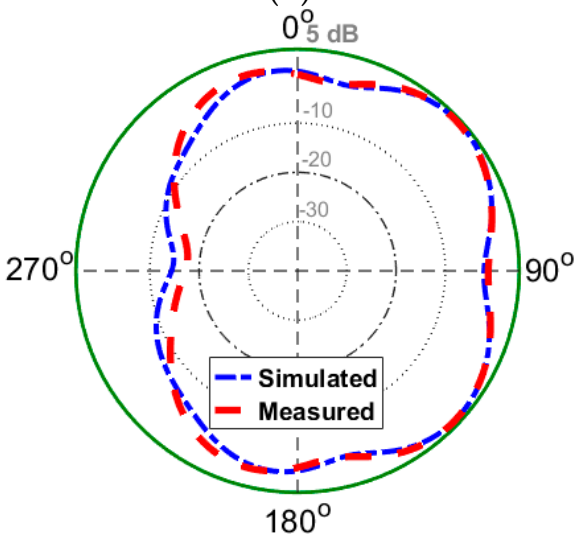

(d)

Figure 15. 2D radiation patterns for (a) Ant.1 at $3.6 \mathrm{GHz}$, (b) Ant.2 at $3.6 \mathrm{GHz}$, (c) Ant.1 at $4 \mathrm{GHz}$ and (d) Ant.2 at $4 \mathrm{GHz}$.

Table 2. Comparison between our design and the referenced 5G smartphone antennas.

\begin{tabular}{|c|c|c|c|c|c|c|}
\hline Reference & Design Type & Bandwidth (GHz) & Efficiency (\%) & Size $\left(\mathrm{mm}^{2}\right)$ & Isolation (dB) & ECC \\
\hline [11] & Gap-Coupled IFA & $3.4-3.6$ & - & $150 \times 75$ & 15 & $<0.02$ \\
\hline [12] & Inverted-F & $3.4-3.6$ & $55-60$ & $100 \times 50$ & 10 & - \\
\hline [14] & Monopole & $3.4-3.6$ & $35-50$ & $150 \times 75$ & 11 & $<0.40$ \\
\hline [15] & Spatial-Reuse Antenna & $3.4-3.6$ & $40-70$ & $150 \times 75$ & 12 & $<0.2$ \\
\hline [16] & Inverted-L Monopole & $3.4-3.6$ & $40-60$ & $136 \times 68$ & 14 & $<0.2$ \\
\hline [19] & Monopole & $4.55-4.75$ & $50-70$ & $136 \times 68$ & 10 & - \\
\hline [20] & Tightly Arranged Pairs & $3.4-3.6$ & $50-70$ & $150 \times 73$ & 17 & $<0.07$ \\
\hline [21] & Wave-Guide & $3.4-3.6$ & $50-80$ & $150 \times 75$ & 15 & $<0.2$ \\
\hline [22] & Monopole & $3.4-3.6$ & $60-70$ & $150 \times 75$ & 18 & $<0.015$ \\
\hline [23] & Diamond-shaped Slot & $3.3-3.9$ & $60-80$ & $150 \times 75$ & 17 & $<0.01$ \\
\hline [24] & open-end slot & $3.4-3.6$ & $50-60$ & $136 \times 68$ & 11 & 0.05 \\
\hline
\end{tabular}




\section{User Impacts on the Performance of the CPW-fed Smartphone Antenna Array}

For smartphone antennas, it is indispensable to investigate the user effect on the radiation performance of the antenna [41,42]. Different usage postures in data-mode and talk-mode are considered in this section. Figure 16 represents $S_{n n}$ and efficiency results of the $5 G$ antenna in data-mode with different placement modes for right/left hands touching the top/bottom sides of the smartphone. It can be observed that similar characteristics are achieved for different data-mode scenarios. This is mainly due to symmetrical configuration and similar placements of the CPW-fed antenna pairs. In addition, as shown in Figure $16 \mathrm{~b}$, the $S_{\text {nn }}$ results of all elements are not influenced significantly and still could cover the desired operation band. Some variation is discovered for the elements, which are partially covered with the hand-phantom, due to its absorption. Furthermore, it is evident from Figure 16c that a part of the radiation power of the antenna is absorbed by the medium, which causes some reduction in the efficiencies of the elements. However, the elements still provide around $40 \%$ and more total efficiencies within the 3.4-4.4 GHz operation band.

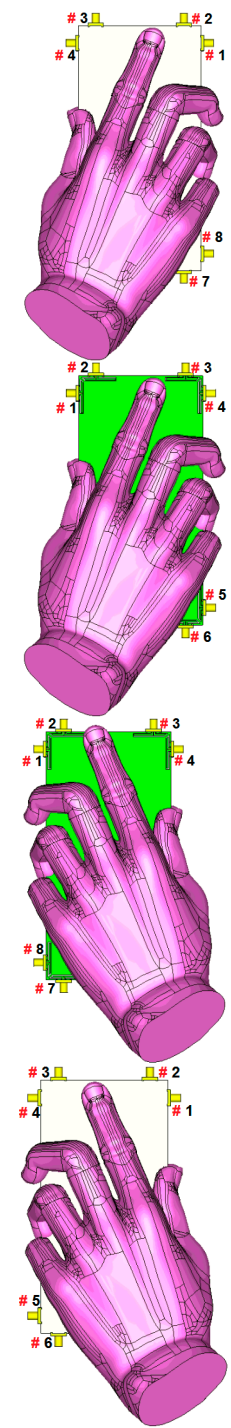

(a)
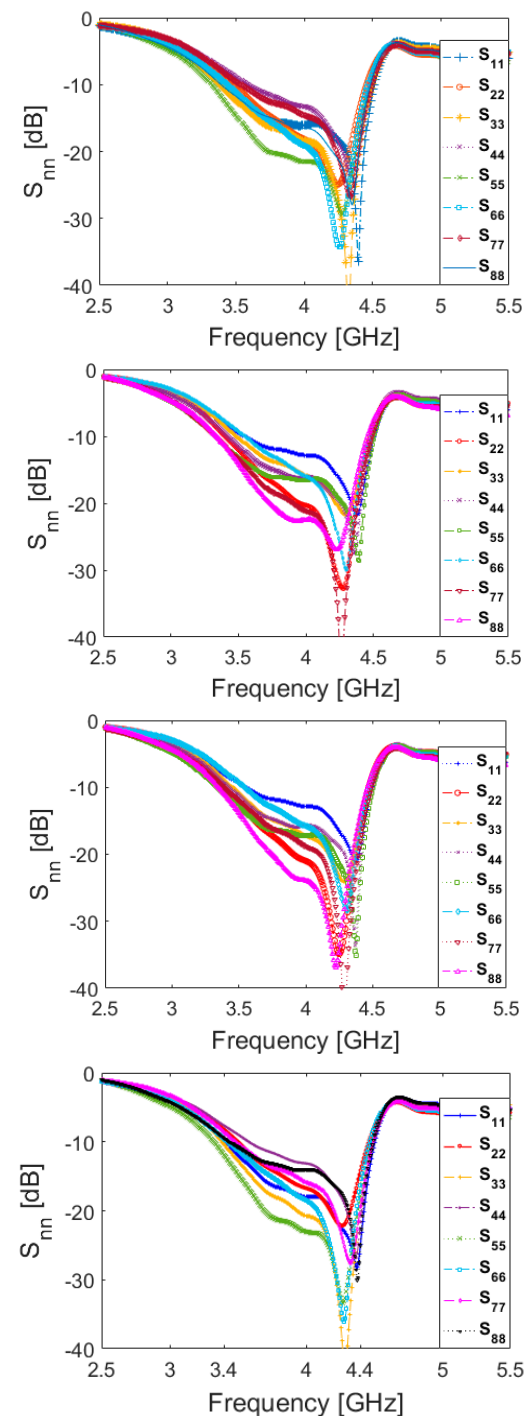

(b)
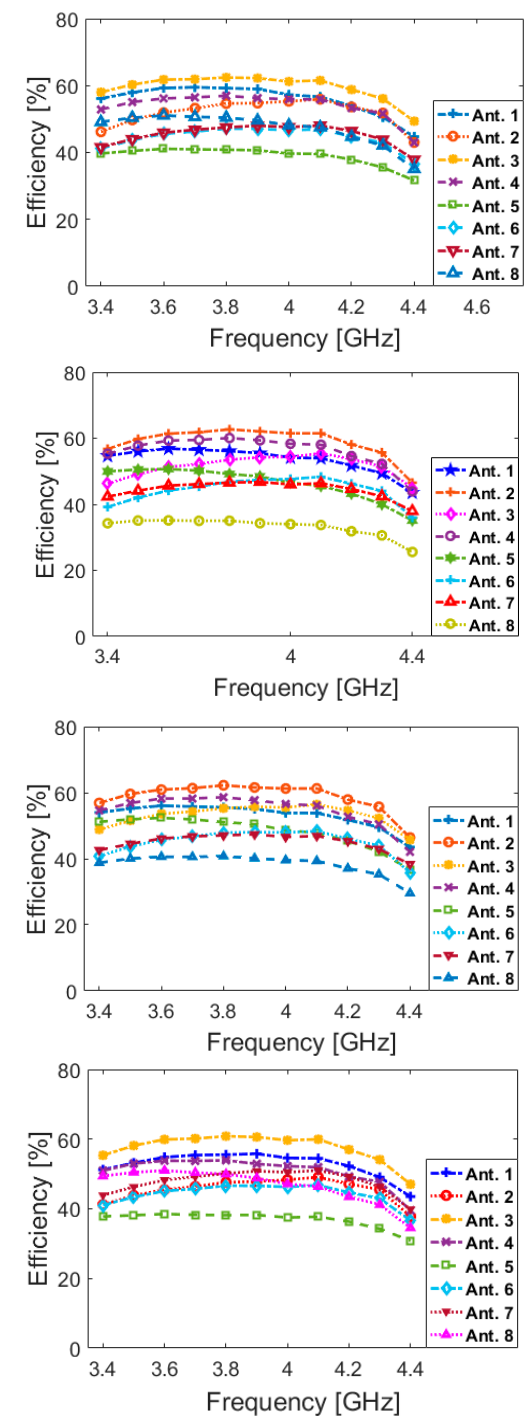

(c)

Figure 16. (a) Placement, (b) $S_{\mathrm{nn}}$ and (c) total efficiencies for different data-mode scenarios.

Apart from the data-mode, discussed above, the characteristics of the CPW-fed resonators in talk-mode are also investigated and represented in Figures 17-19. It is evident from Figure 17 that the antenna elements work sufficiently and provide good $S_{\mathrm{nn}}$ and total efficiency results for different 
antenna elements. The radiation pattern results for the MIMO smartphone antenna in talk-mode are shown in Figure 18. As can obviously be realized from the simulation, the proposed CPW-fed MIMO antenna offers good radiation patterns in talk-mode. In addition, the gain levels of the CPW-fed antenna resonators vary from 2 to $5 \mathrm{GHz}$.

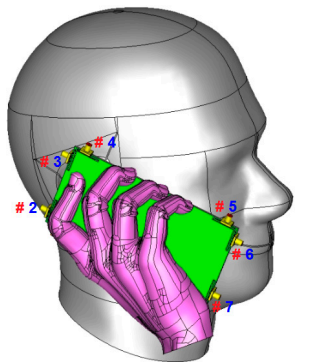

(a)

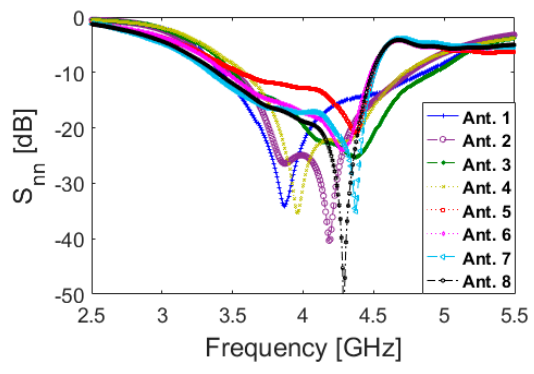

(b)

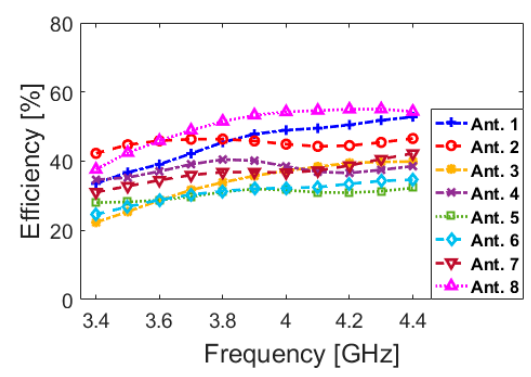

(c)

Figure 17. (a) Placement, (b) $S_{n n}$ and (c) total efficiencies for talk-mode.

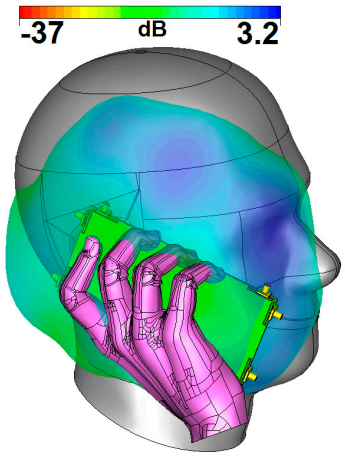

\# Ant. 1

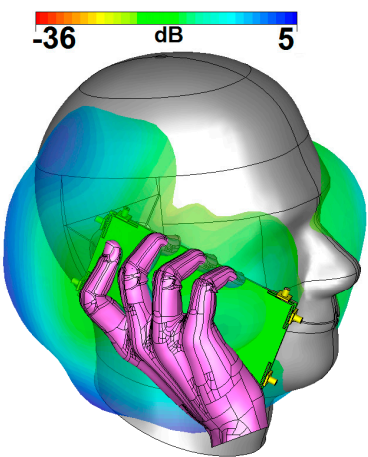

\# Ant. 5

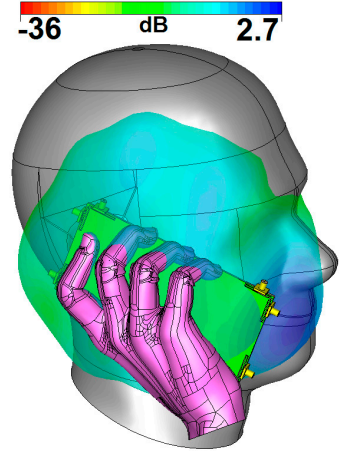

\# Ant. 2

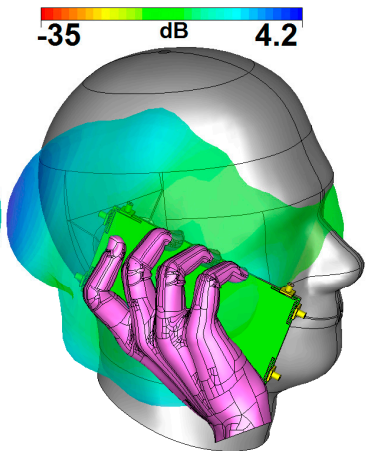

\# Ant. 6

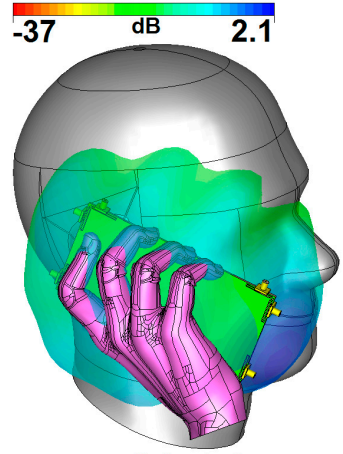

\# Ant. 3

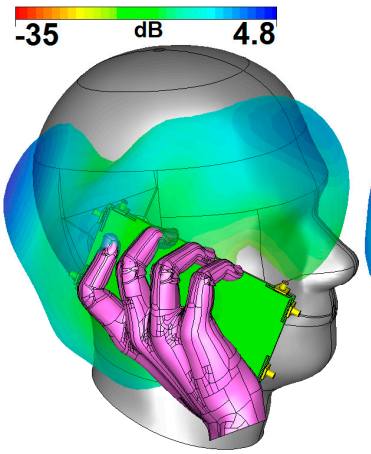

\# Ant. 7

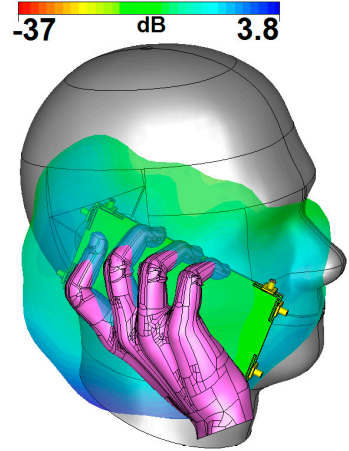

\# Ant. 4

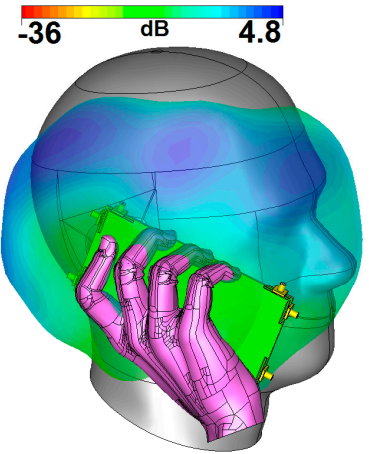

\# Ant. 8

Figure 18. Radiation patterns in Talk-Mode.

Compared with Figure 8, the maximum reduction of antenna gain is observed for the elements closely spaced with the user's head and hand. In general, the closer the distance between the antenna element and the user's hand/head is, the greater the reduction on the gain and the efficiencies [43]. As can be observed, the maximum reductions of the gain levels are discovered for the elements that are located near to the head phantom (Ant. 3). In addition, due to the presence of the head and hand phantoms, the radiation patterns are a bit distorted and become weaker. One can see that antenna elements are touched by different parts of the hand and head phantoms in the presented talk-mode.

The specific absorption rate (SAR) characteristic of the CPW-fed MIMO design is studied and represented in Figure 19. It is shown that Ant. 3 causes the maximum SAR value (2.1), and the minimum SAR value (0.7) is observed from Ant. 7. Therefore, it can be concluded that the closest 
distance between antenna elements and the user-head leads to a maximum SAR value, and the furthest distance leads to a minimum SAR value [44,45].

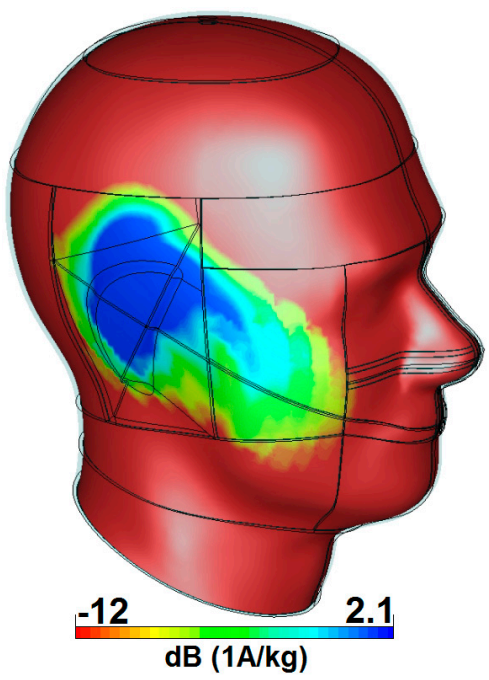

(a)

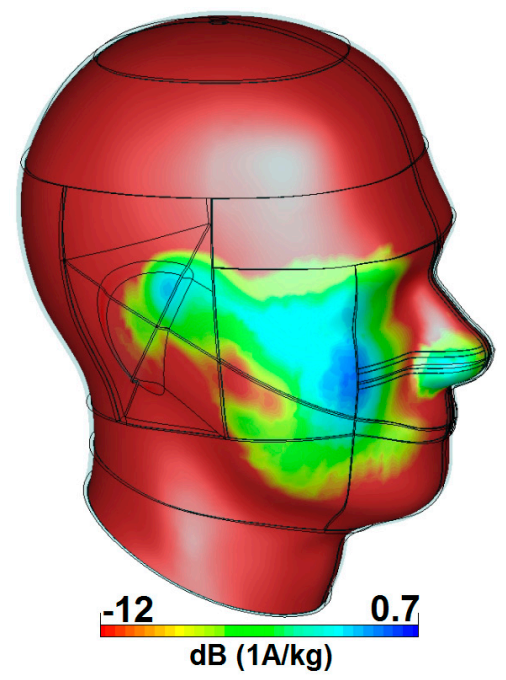

(b)

Figure 19. Specific absorption rate (SAR) investigations for (a) Ant. 3 and (b) Ant. 7.

The $S_{n n}\left(S_{11} \sim S_{88}\right)$ and efficiency characteristics of the CPW-fed MIMO smartphone antenna in the presence of battery, speaker, camera, USB connector and LCD screen are investigated and illustrated in Figure 20. It was found that the designed CPW-fed MIMO antenna provides sufficient $S_{n n}$ and efficiencies supporting a 3.4-4.4 GHz band. In addition, as shown in Figure 20c, the array exhibits high efficiencies in the presence of smartphone components.

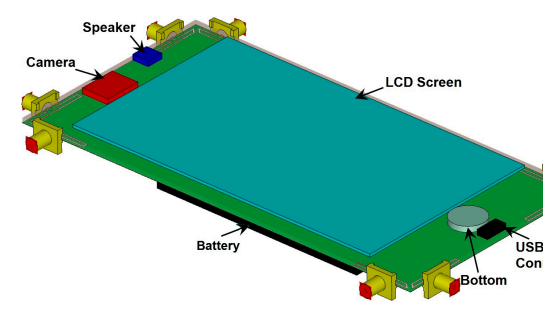

(a)

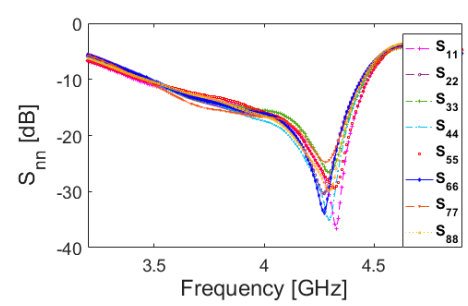

(b)

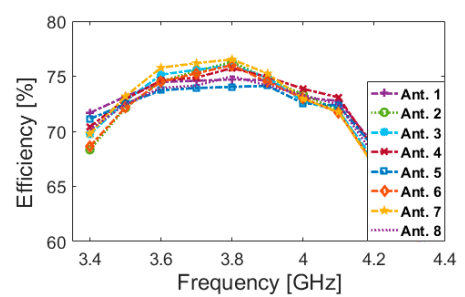

(c)

Figure 20. (a) Schematic, (b) $S_{n n}$ and (c) efficiencies of the array in the presence of the smartphone components.

\section{Conclusions}

A smartphone array antenna design with new double-fed CPW-fed resonators is introduced for sub-6 GHz 5G applications. The structure of the CWP-fed element consists of two closely-spaced modified T-ring radiators operating with a frequency band of 3.3-4.4 GHz. Four pairs of the CPW-fed diversity antennas are placed at four corners of the smartphone board to form an $8 \times 8 \mathrm{MIMO}$ antenna. The fundamental characteristics and MIMO performance of the design were studied and sufficient results were achieved. Simulated and experimental results are provided to validate the usefulness of the designed smartphone antenna array for $5 \mathrm{G}$ mobile communications.

Author Contributions: Writing-original draft preparation, N.O.P., Y.I.A.A.-Y., A.M.A., M.P. and R.A.A.-A.; writing-review and editing, N.O.P., H.J.B. and R.A.A.-A.; investigation, N.O.P., H.J.B., M.P. and Y.I.A.A.-Y.; resources, N.O.P., M.P. and R.A.A.-A.; for other cases, all authors have participated. All authors have read and agreed to the published version of the manuscript. 
Funding: This project has received funding from the European Union's Horizon 2020 research and innovation program under grant agreement H2020-MSCA-ITN-2016 SECRET-722424.

Acknowledgments: The authors wish to express their thanks to the support provided by the innovation program under grant agreement H2020-MSCA-ITN-2016 SECRET-722424.

Conflicts of Interest: The authors declare no conflict of interest.

\section{References}

1. Nadeem, Q.U.A.; Kammoun, A.; Debbah, M.; Alouini, S.-M. Design of 5G full dimension massive MIMO systems. IEEE Trans. Commun. 2018, 66, 726-740. [CrossRef]

2. Ojaroudiparchin, N.; Shen, M.; Pedersen, G.F. Multi-layer 5G mobile phone antenna for multi-user MIMO communications. In Proceedings of the 23rd Telecommunications Forum Telfor (TELFOR), Belgrade, Serbia, 24-26 November 2015; pp. 559-562.

3. Osseiran, A.; Boccardi, F.; Braun, V.; Kusume, K.; Marsch, P.; Maternia, M.; Queseth, O.; Schellmann, M.; Schotten, H.; Taoka, H.; et al. Scenarios for 5G mobile and wireless communications: The vision of the METIS project. IEEE Commun. Mag. 2014, 52, 26-35. [CrossRef]

4. Yang, H.H.; Quel, Y.Q.S. Massive MIMO Meet Small Cell. SpringerBriefs Electr. Comput. Eng. 2017. [CrossRef]

5. Ojaroudi, N.; Ghadimi, N. Design of CPW-fed slot antenna for MIMO system applications. Microw. Opt. Technol. Lett. 2014, 56, 1278-1281. [CrossRef]

6. Parchin, N.O.; Basherlou, H.J.; Al-Yasir, Y.I.A.; Abd-Alhameed, R.A.; Abdulkhaleq, A.M.; Noras, J.M. Recent developments of reconfigurable antennas for current and future wireless communication systems. Electronics 2019, 8, 128. [CrossRef]

7. Hussain, R.; Alreshaid, A.T.; Podilchak, S.K.; Sharawi, M.S. Compact 4G MIMO antenna integrated with a 5G array for current and future mobile handsets. IET Microw. Antennas Propag. 2017, 11, 271-279. [CrossRef]

8. Ojaroudi, N.; Ojaroudi, H.; Ghadimi, N. Quadband planar inverted-f antenna (PIFA) for wireless communication systems. Prog. Electromagn. Res. Lett. 2014, 45, 51-56. [CrossRef]

9. Chen, Q.; Lin, H.; Wang, J.; Ge, L.; Li, Y.; Pei, T.; Sim, C.-Y.-D. Single ring slot based antennas for metal-rimmed 4G/5G smartphones. IEEE Trans. Antennas Propag 2018, 67, 1476-1487. [CrossRef]

10. Ojaroudiparchin, N.; Shen, M.; Pedersen, G.F. Wide-scan phased array antenna fed by coax-to- microstriplines for 5G cell phones. In Proceedings of the 21st International Conference on Microwaves, Radar and Wireless Communications, krakow, Poland, 9-11 May 2016.

11. Liu, Y.; Lu, Y.; Zhang, Y.; Gong, S.-X. MIMO antenna array for 5G smartphone applications. In Proceedings of the 13th European Conference on Antennas and Propagation (EuCAP), Krakow, Poland, 31 March-5 April 2019.

12. Al-Hadi, A.A.; Ilvonen, J.; Valkonen, R.; Viikan, V. Eight-element antenna array for diversity and MIMO mobile terminal in LTE 3500MHz band. Microw. Opt. Technol. Lett. 2014, 56, 1323-1327. [CrossRef]

13. Parchin, N.O.; Al-Yasir, Y.I.A.; Noras, J.M.; Abd-Alhameed, R.A. Dual-polarized MIMO antenna array design using miniaturized self-complementary structures for 5G smartphone applications. In Proceedings of the 13th European Conference on Antennas and Propagation (EuCAP), Krakow, Poland, 31 March-5 April 2019.

14. Wong, K.-L.; Lu, J.-Y.; Chen, L.-Y.; Li, W.Y.; Ban, Y.L. 8-antenna and 16-antenna arrays using the quad-antenna linear array as a building block for the 3.5-GHz LTE MIMO operation in the smartphone. Microw. Opt. Technol. Lett. 2016, 58, 174-181. [CrossRef]

15. Chang, L.; Yu, Y.; Wei, K.; Wang, H. Polarization-orthogonal co-frequency dual antenna pair suitable for 5G MIMO smartphone with metallic bezels. IEEE Trans. Antennas Propag. 2019, 67, 5212-5220. [CrossRef]

16. Abdullah, M.; Ban, Y.-L.; Kang, K.; Li, M.-Y.; Amin, M. Eight-element antenna array at 3.5GHz for MIMO wireless application. Prog. Electromagn. Res. C 2017, 78, 209-217. [CrossRef]

17. Zhao, X.; Yeo, S.P.; Ong, L.C. Decoupling of inverted-F antennas with high-order modes of ground plane for 5G mobile MIMO platform. IEEE Trans. Antennas Propag. 2018, 66, 4485-4495. [CrossRef]

18. Parchin, N.O.; Al-Yasir, Y.I.A.; Ali, A.H.; Elfergani, I.; Noras, J.M.; Rodriguez, J.; Abd-Alhameed, R.A.; Al-Yasir, Y.I.A. Eight-element dual-polarized MIMO slot antenna system for 5G smartphone applications. IEEE Access 2019, 9, 15612-15622. [CrossRef]

19. Xu, S.; Zhang, M.; Wen, H.; Wang, J. Deep-subwavelength decoupling for MIMO antennas in mobile handsets with singular medium. Sci. Rep. 2017, 7, 12162. [CrossRef] 
20. Sun, L.; Feng, H.; Li, Y.; Zhang, Z. Compact 5G MIMO mobile phone antennas with tightly arranged orthogonal-mode pairs. IEEE Trans. Antennas Propag. 2018, 66, 6364-6369. [CrossRef]

21. Li, M.-Y.; Ban, Y.-L.; Xu, Z.-Q.; Guo, J.; Yu, Z.-F. Tri-polarized 12-antenna MIMO array for future 5G smartphone applications. IEEE Access 2018, 6, 6160-6170. [CrossRef]

22. Zhao, A.; Zhouyou, R. Size reduction of self-isolated MIMO antenna system for $5 \mathrm{G}$ mobile phone applications. IEEE Antennas Wirel. Propag. Lett. 2019, 18, 152-156. [CrossRef]

23. Parchin, N.O.; Basherlou, H.J.; Alibakhshikenari, M.; Parchin, Y.O.; Al-Yasir, Y.I.A.; Abd-Alhameed, R.A.; Limiti, E. Mobile-phone antenna array with diamond-ring slot elements for $5 \mathrm{G}$ massive MIMO systems. Electronics 2019, 8, 521. [CrossRef]

24. Abdullah, M.; Kiani, S.H.; Abdulrazak, L.F.; Iqbal, A.; Bashir, M.A.; Khan, S.; Kim, S. High-performance multiple-input multiple-output antenna system for 5G mobile terminals. Electronics 2019, 8, 1090. [CrossRef]

25. Jiang, W.; Liu, B.; Cui, Y.; Hu, W. High-isolation Eight-Element MIMO array for 5G smartphone applications. IEEE Access 2019, 7, 34104-34112. [CrossRef]

26. Statement: Improving Consumer Access to Mobile Services at $3.6 \mathrm{GHz}$ to $3.8 \mathrm{GHz}$. Available online: https://www.ofcom.org.uk/consultations-and-statements/category-1/future-use-at-3.6-3.8-ghz (accessed on 21 October 2018).

27. Ojaroudi, N.; Ghadimi, N. Dual-band CPW-fed slot antenna for LTE and WiBro applications. Microw. Opt. Technol. Lett. 2014, 56, 1013-1015. [CrossRef]

28. Ojaroudi, N. Small microstrip-fed slot antenna with frequency band-stop function. In Proceedings of the 21th Telecommunications Forum. TELFOR 2013, Belgrade, Serbia, 27-28 November 2013.

29. Ojaroudi, N. Design of microstrip antenna for 2.4/5.8 GHz RFID applications. In Proceedings of the German Microwave Conference, GeMic 2014, RWTH Aachen University, Aachen, Germany, 10-12 March 2014.

30. Valizade, A.; Ghobadi, C.; Nourinia, J.; Parchin, N.O.; Ojaroudi, M. Band-notch slot antenna with enhanced bandwidth by using $\Omega$-shaped strips protruded inside rectangular slots for UWB applications. Appl. Comput. Electromagn. Soc. (ACES) J. 2012, 27, 816-822.

31. CST Microwave Studio; ver. 2018; CST: Framingham, MA, USA, 2018.

32. Al-Nuaimi, M.K.T.; Whittow, W.G. Performance investigation of a dual element ifa array at 3 ghz for mimo terminals. In Proceedings of the Antennas and Propagation Conference (LAPC), Loughborough, UK, 14-15 November 2011.

33. Parchin, N.O.; Basherlou, H.J.; Abd-Alhameed, R.A.; Noras, J.M. Dual-band monopole antenna for RFID applications. Future Internet 2019, 11, 31. [CrossRef]

34. Sharawi, M.S. Printed multi-band MIMO antenna systems and their performance metrics [wireless corner]. IEEE Antennas Propag. Mag. 2013, 55, 218-232.

35. Ojaroudiparchin, N.; Shen, M.; Pedersen, G.F. Small-size tapered slot antenna (TSA) design for use in 5G phased array applications. Appl. Comput. Electromagn. Soc. J. 2018, 32, 193-202.

36. Mazloum, J.; Ghorashi, A.; Ojaroudi, M.; Ojaroudi, N. Compact triple-band S-shaped monopole diversity antenna for MIMO applications. Appl. Comput. Electromagn. Soc. J. 2015, 30, 975-980.

37. Ojaroudiparchin, N.; Shen, M.; Zhang, S.; Pedersen, G.F. A switchable 3-D-coverage-phased array antenna package for 5G mobile terminals. IEEE Antennas Wireless Propag. Lett. 2016, 15, 1747-1750. [CrossRef]

38. Parchin, N.O.; Alibakhshikenari, M.; Basherlou, H.J.; Abd-Alhameed, R.A.; Rodriguez, J.; Limiti, E. MM-wave phased array quasi-yagi antenna for the upcoming 5G cellular communications. Appl. Sci. 2019, 9, 978. [CrossRef]

39. Elfergani, I.T.E.; Hussaini, A.S.; Rodriguez, J.; Abd-Alhameed, R. Antenna Fundamentals for Legacy Mobile Applications and Beyond; Springer: Switzerland, 2017; pp. 1-659.

40. Ojaroudi, N.; Ojaroudi, Y.; Ojaroudi, S. Compact ultra-wideband monopole antenna with enhanced bandwidth and dual band-stop properties. Int. J. RF Microw. Comput. Aided Eng. 2014, 25, 346-357. [CrossRef]

41. Ojaroudi, N.; Yazdanifard, S.; Ojaroudi, N.; Naser-Moghaddasi, M. Enhanced bandwidth of small square monopole antenna by using inverted Ushaped slot and conductor-backed plane. Appl. Comput. Electromagn. Soc. (ACES) J. 2012, 27, 685-690.

42. Syrytsin, I.; Zhang, S.; Pedersen, G.F. Performance investigation of a mobile terminal phased array with user effects at 3.5 GHz for LTE advanced. IEEE Antennas Wirel. Propag. Lett. 2017, 16, 1847-1850. [CrossRef] 
43. Ojaroudiparchin, N.; Shen, M.; Pedersen, G.F. Design of Vivaldi antenna array with end-fire beam steering function for $5 \mathrm{G}$ mobile terminals. In Proceedings of the 23rd Telecommunications Forum Telfor (TELFOR), Belgrade, Serbia, 24-26 November 2015; pp. 587-590.

44. Hussain, R.; Sharawi, M.S.; Shamim, A. 4-element concentric pentagonal slot-line-based ultra-wide tuning frequency reconfigurable MIMO antenna system. IEEE Trans. Antennas Propag. 2018, 66, 4282-4287. [CrossRef]

45. Parchin, N.O.; Ullah, A.; Asharaa, A.S.; Al-Yasir, Y.I.A.; Jahanbakhsh, H.; Nagala, M.; Abd-Alhameed, R.; Noras, J. 8×8 MIMO antenna system with coupled-fed elements for 5G handsets. In Proceedings of the IET Antennas and Propagation Conference, Birmingham, UK, 11-12 November 2019.

(C) 2020 by the authors. Licensee MDPI, Basel, Switzerland. This article is an open access article distributed under the terms and conditions of the Creative Commons Attribution (CC BY) license (http://creativecommons.org/licenses/by/4.0/). 